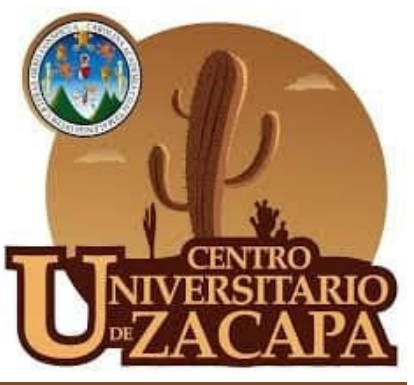

Silvia Judith Palma Morales

Liliana Elizabeth Monroy Díaz

Jim Roberto Castillo Mendoza

Dick Randolfo Guillén Dardón

Ingrid Irlanda Balán González

Referencia del ensayo

Ensayo científico

Recibido: 15/11/2020

Publicado: 16/01/2021

\title{
Efecto de la Neuroeducación en tiempos de
} Pandemia

\author{
Effect of Neuroeducation in time of Pandemic
}

Palma Morales, S. J., Monroy Díaz, L. E., Castillo Mendoza, J. R., Guillén Dardón, D. R., y Bálan González, I. I. (2021). Efecto de la Neuroeducación en tiempos de Pandemia. Revista Académica CUNZAC, 4(1). 59-64. DOI: https://doi.org/10.46780/cunzac.v4i1.33

Resumen

La Neuroeducación encontró diversos desafíos para contribuir al proceso enseñanza-aprendizaje, debido a distintos factores contextuales y emocionales que obstaculizaron su aplicación en las distintas metodologías de estudio. Componentes socioculturales limitaron el acceso a una parte de la población estudiantil guatemalteca a teléfonos y computadoras de gama alta, siendo indispensables para sus clases virtuales o híbridas. Estos elementos también generaron frustración en cuidadores y educadores debido a la escasa o nula capacitación para su manejo. Una metodología ortodoxa que valora más en términos cuantitativos que cualitativos al estudiante, deponiendo su humanidad, anulando o invalidando sus emociones que por consecuencia de la pandemia y el estrés generado en casa y en el ambiente escolar no son apreciadas dentro del desarrollo cognitivo del estudiante, ignorando que son fundamentales para un exitoso proceso enseñanza-aprendizaje. La impotencia de padres, cuidadores y educadores, se desplaza a los niños y adolescentes que en su afán de preservación ignoran el aprendizaje escolar. Literatura diversa aunada a conversatorios con educadores y padres de familia nos llevaron a concluir que el conocimiento del cerebro y su incidencia en la conducta es indispensable para adecuar metodologías de estudio individualizadas sin ignorar las emociones y el juego como precursor y base del aprendizaje.

Palabras clave: pandemia, neuroeducación, efectos

\begin{abstract}
Neuroeducation encountered various challenges to contribute to the teaching-learning process, due to different contextual and emotional factors that hindered its application in the different study methodologies. Sociocultural components limited access to a part of the Guatemalan student population to telephones and high-end computers, being essential for their virtual or hybrid classes. These elements also generated frustration in caregivers and educators due to little or no training in their management. An orthodox methodology that values the student more in quantitative than qualitative terms, laying down his humanity, nullifying or invalidating his emotions that as a consequence of the pandemic and the stress generated at home and in the school environment are not appreciated within the cognitive development of the student, ignoring that they are essential for a successful teaching-learning process. The impotence of parents, caregivers and educators, displaces children and adolescents who, in their quest for preservation, ignore school learning. Diverse literature coupled with conversations with educators and parents led us to conclude that knowledge of the brain and its impact on behavior is essential to adapt individualized study methodologies without ignoring emotions and play as a precursor and basis for learning.
\end{abstract}

Keywords: pandemic, neuroeducation, effect

\begin{tabular}{l|l|l|l|l|l|l}
\hline CUNZAC & Revista del Centro Universitario de Zacapa & ISSN: 2708-7158 & Volumen 4 & Enero - Junio 2021 \\
\hline
\end{tabular}




\section{Introducción}

Como consecuencia de la pandemia covid-19, en nuestro contexto social guatemalteco se dictaron medidas restrictivas afectando la cotidianidad del ciudadano; el confinamiento provocó alteraciones en las actividades escolares, culturales, religiosas, comerciales, entre otras. En el sector educativo, el proceso de enseñanza-aprendizaje enfrentó desafíos; las formas y los medios.

Las formas se limitaron a una interacción a distancia y los medios se transformaron en textos, plataformas y dispositivos digitales provocando un distanciamiento social entre docentes y estudiantes. La nueva modalidad virtual planteó desafíos para los padres también y en consecuencia por el desempleo o pocos ingresos en el hogar aunado una falta de interés o frustración en el estudiante, algunos optaron por realizar actividades laborales que permitieron aportar ingresos económicos a la familia, dando como resultado que el proceso de aprendizaje quedará delegado a última instancia.

Se pretende reseñar el impacto de los efectos de la Neuroeducación durante y después de la pandemia. En el sector educativo con la integración de la tecnología tanto docentes como estudiantes modificaron y reestructuraron sus propias funciones cognitivas.

La educación en el siglo XXI, plantea retos, aceptando la realidad social en escuelas públicas y privadas de Guatemala. Con la integración de la tecnología a la educación resurgen aspectos sociales no tan favorecedores; partamos de la economía, donde un gran porcentaje de la población guatemalteca, vive en el área rural con altos índices de pobreza, según diversos análisis y estudios consultados los cuales impiden que se tenga acceso al internet o se realice de manera restringida, por medio de tarjetas prepago.

Otro aspecto relacionado a la tecnología son los dispositivos electrónicos como celulares de baja gama y computadoras con cámara integrada, lo cual continúa interfiriendo en el proceso enseñanza-aprendizaje virtual, pues el alumno posee una computadora, pero carente de todos los requerimientos para una conexión exitosa. La educación pública es el sector directamente afectado, pues carecen de tecnología, aunado a esto los educadores y padres encargados, carecen de capacitación para el uso de las plataformas virtuales.

En cuanto a los a los aspectos psico-emocionales básicos para la adquisición del aprendizaje en general y en términos escolares habrá que resaltar que el desarrollo responsable de la Neuroeducación tendrá que proponer la valoración y respeto por el desarrollo evolutivo de cada niño e involucrar las emociones y características de personalidad, mismas que están ligadas al proceso de enseñanza-aprendizaje. Para ello se debe plantear un modelo de trabajo tecnológico y a su vez presencial donde a través del juego, la interacción y la innovación en contenidos, permitan que el alumno sea estimulado emocional y conductualmente en los aspectos relevantes para el desarrollo de la interacción social. El movimiento, planificación, resolución de problemas y atención, se encuentran implícitos en el proceso neurocognitivo y psicopedagógico en los salones de clases y ahora se tendrán que adaptar a la modalidad virtual o híbrida en el modelo de enseñanza.

Además, en nuestro contexto educativo, rige una metodología ortodoxa que discrimina a un sector de la población infantil, entre ellos niños que presentan dificultades en el aprendizaje o problemas del neurodesarrollo entre Enero - Junio 2021 
otros. La Neuroeducación es considerada como un factor altamente influyente y positivo para contribuir y mejorar en el proceso de inclusión en el aula, proponiendo metodologías actualizadas basadas en el desarrollo de habilidades cognitivas superiores y sobre todo una concientización social sobre la importancia de una oportuna estimulación en edades o etapas tempranas en el desarrollo evolutivo del niño.

La incidencia del trabajo de los padres o cuidadores será siempre un punto clave en el desarrollo y el aprendizaje significativo en el contexto de la educación. Este análisis considera evaluar también la relación entre híper estimulación cognitiva en los niños desde las etapas iniciales del desarrollo, hasta la adolescencia y si el uso excesivo de las pantallas, la nutrición, y el contexto sociocultural influyen en el desbordamiento de emociones que proyectan resultados pocos favorecedores para el desarrollo de habilidades cognitivas y especialmente en las funciones ejecutivas superiores, necesarias para un adecuado desempeño escolar.

\section{Contenido}

Con el desarrollo de la Neurociencia, el conocimiento del funcionamiento del cerebro avanzó más y su atención en el ámbito educativo concibió a la Neuroeducación, integrada por la Pedagogía, Psicología y por supuesto la Neurociencia, siendo la intermediaria entre emociones, conducta, procesos mentales y relaciones interpersonales con en el proceso enseñanza- aprendizaje que constituyen el campo de abordaje fértil para los educandos de niveles pre escolares a un el ciclo de enseñanza media.

Las problemáticas latentes en la población guatemalteca, aunadas a la crisis de salud por la pandemia Covid 19 y ante una nueva realidad, el contexto social y cultural condicionan a los estudiantes para que cuantitativamente su rendimiento escolar sea valorado, ignorando que la presión para ajustarse y adaptarse al medio ha desencadenado frustración y estrés no solamente en los educandos, sino en padres y educadores; proyectando resultados poco alentadores como la deserción escolar, problemas de aprendizaje, bajo rendimiento escolar, ansiedad, depresión y la inatención provocada por la falta de motivación intrínseca y extrínseca, (Moreira, 2020).

La escasa o nula capacitación de educadores para aplicar los conocimientos de la Neuroeducación en el aula en la modalidad hibrida o virtual, obstaculizan los efectos positivos en el modelo enseñanza- aprendizaje pues no poseen los recursos necesarios para apoyar a la población infantil, (Braidot, 2013).

En el ámbito socioeducativo cualquier intervención, proceso de desarrollo e incidencia que el individuo manifiesta en las diferentes etapas de la vida, genera plasticidad cerebral y neurogénesis (generación de nuevas neuronas), facilitando el aprendizaje, permitiendo al alumno adaptarse al medio. El confinamiento por covid-19 generó nuevos abordajes para el aprendizaje creando controversia y disminución en el desarrollo de habilidades interpersonales que reúnen aspectos relevantes y que ejercen influencia en la adquisición de conocimientos, como la colaboración, el trabajo en equipo, la solidaridad y la empatía.

La presión ejercida al estudiante por su entorno provocará efectos positivos o negativos en la estructura de su personalidad, misma que influenciará el desarrollo y adecuado ajuste en diferentes ámbitos, se resalta que los efectos positivos que la Neuroeducación durante la pandemia pudo aportar, han sufri-

Enero - Junio 2021 
do un desplazamiento, pues se antepone una metodología educativa tradicionalista que limita su aplicación en el estudiante y en la enseñanza. La Neuroeducación se encuentra ante una dicotomía, en donde la prioridad actual es la preservación de la vida, entonces los recursos cognitivos como atención, memoria, entre otros están enfocados en salvaguardar la vida, la educación pasa a un segundo plano, pero solo en la mente del niño. Sus emociones son invalidadas y enfrentan sobrecargas de tareas 0 actividades repetitivas y carentes de significado que solo enfocan en aquello que "debería hacer" y no en lo que el propio estudiante es capaz de hacer, sacrificando las expectativas a largo plazo por los resultados inmediatos.

Para el niño el movimiento y la exploración del ambiente son necesarios, según Colling, "El maestro debe cuidarse de reprimir excesivamente y sofocar la actividad motora del niño" el juego puede ser un aliado para la transmisión de conocimientos, relaja, mejora interacción social, se involucran emociones como la alegría. Ante un juego novedoso el niño despierta su atención y curiosidad, aspectos involucrados en el aprendizaje. Un ambiente familiar desorganizado y estresante provoca en el niño agitación motora y esto a su vez estrés. Es una realidad actual en los hogares, donde el desconocimiento en el manejo de la tecnología provoca impotencia en los cuidadores, más las limitaciones económicas, aunado a un educador rígido y controlador terminan desencadenando el fracaso escolar (Colling, 1975).

La educación es un proceso dinámico, la metodología híbrida presenta ventajas y desventajas puesto que, al implementarse como método alternativo, permite que la transmisión de conocimientos de docentes a alumnos no sea interrumpido, evitando la exposición al contagio masivo del virus. Los avances científicos demandan docentes vanguardistas, que conozcan la función de estructuras cerebrales, facilitando un espacio estimulante en el ámbito escolar. La Neuroeducación, orienta al estudio de la conducta, la atención la memoria y la percepción, como procesos cognitivos básicos y superiores. Los docentes que se apoyan en la Neuroeducación adquieren conocimientos para activar las áreas implicadas en el proceso de aprendizaje para fortalecer las habilidades cognitivas, sociales, físicas y emocionales en los estudiantes.

Claro es, que este desarrollo positivo se verá marcado por un ambiente dinámico basado en la normalidad que ha gozado a lo largo de la vida; y que en este caso a raíz de una pandemia se transformó. Además, el estrés generado en los adultos influye al mismo tiempo en los niños, la presión de los padres y educadores provocan inestabilidad emocional y el exceso de cortisol desencadenará problemas con la retentiva o memoria a corto plazo y posterior evocación de información.

A raíz del confinamiento varios países a nivel mundial optaron por la utilización de dispositivos móviles para dar continuidad al proceso educativo y debido a los acuerdos que UNES$\mathrm{CO}$ ha manifestado en diversas ocasiones acerca de las necesidades de la era actual, se implementan las nuevas tecnologías de la información y comunicación, como m-learning y e-learning, reconociendo la gama de beneficios con el uso de pantallas, en una contraparte éstos inciden de manera negativa en el adecuado desempeño escolar y aunque no exista un tiempo establecido para que los niños utilicen una pantalla analógica, es un cuestionamiento que nos planteamos, debido a los riesgos que esto conlleva, incluso existen estudios afirmando que las pantallas son herramientas debilitadoras del desarrollo cognitivo, especialmente en el lenguaje social, emocional y oral (Mora, 2014). 
El tiempo desmedido en un entorno digital contribuye a los malos hábitos alimentarios y horarios de sueño, esto puede afectar la neuroplasticidad donde el cerebro se estaría adaptando a cambios nocivos alterando diversas conductas. Según los expertos nutriólogos, la comida procesada con bajos nutrientes altera el adecuado desarrollo cerebral. Un balance en los alimentos promueve un ambiente celular fértil para que los procesos mentales como la atención y la concentración tengan un buen desempeño en el ámbito escolar. La ingesta de omega 3 y 6 en completo balance y evitando el consumo de colorantes amarillos que contienen tartrazina, compuesto que provoca trastornos del sueño e hiperactividad y que es común en la dieta de algunos estudiantes.

\section{Conclusión}

En cuanto a los docentes investigar estructuras y funcionamiento cerebral y como la Neuroeducación puede aportar a nuevas metodologías que motiven al estudiante, validando sus emociones y aceptándolas como base para el aprendizaje. La neuroeducación claramente genera impacto positivo cuando al individuo se le estimula a través del juego, la interacción social, la vivencia de experiencias que generen un estrés no toxico, sino que permita a los estudiantes fortalecer habilidades cognitivas y destrezas sociales, a través de la regulación emocional.

La inactividad cerebral producto de un modelo educativo de carácter "híbrido" puede provocar en el estudiante poca estimulación en las áreas cerebrales implícitas en el proceso de enseñanza-aprendizaje. Además, el uso desmedido de dispositivos digitales puede alterar estructuras cerebrales cuyas funciones afectadas serían la memoria, la atención y la motivación, alterando funciones ejecutivas como inhibición de la respuesta y planificación.

Padres y educadores están obligados a establecer y armonizar el ambiente donde se desarrollan los estudiantes, brindando estrategias de afrontamiento ante el estrés y la expresión adecuada de las emociones.

\section{Referencias}

Braidot, N. (2013). Cómo funciona tu cerebro para dummies. Banshee. Obtenido de https://es.pdfdrive.com/c\%C3\%B3 mo-funciona-tu-cerebro-para-dummies-e33998803.html

Collin, G (agosto, 1970) Compendio de Psicología Infantil, Editorial Kapelusz

Mora, F. (2014). Cómo funciona el cerebro. Alianza Editorial. Obtenido de https://www.tagusbooks.com/leer?isb$\mathrm{n}=9788420689487 \& \mathrm{li}=1$ \&idsource $=3001$

Moreira, N. S. (febrero de 2020). Los aportes de la neurociencia en la educación. Revista Atlante: Cuadernos de educación y desarrollo. Obtenido de https://www. eumed.net/rev/atlante/2020/02/aportes-neurociencia-educacion.html

\section{Sobre los autores}

Equipo de investigadores del proyecto "Efecto de la Neuroeducación en tiempos de Pandemia, de la Universidad de San Carlos de Guatemala. 
Copyright (c) (2021) Silvia Judith Palma Morales, Liliana Elizabeth Monroy Díaz, Jim Roberto Castillo Mendoza, Dick Randolfo Guillén Dardón e Ingrid Irlanda Balán González

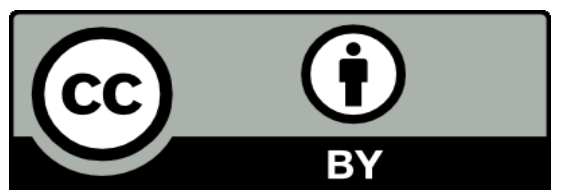

\section{Este texto está protegido por una licencia} Creative Commons 4.0.

Es libre para compartir, copiar y redistribuir el material en cualquier medio o formato y adaptar el documento, remezclar, transformar y crear a partir del material para cualquier propósito, incluso comercialmente, siempre que cumpla la condición de atribución: debe reconocer el crédito de una obra de manera adecuada, proporcionar un enlace a la licencia, e indicar si se han realizado cambios. Puede hacerlo en cualquier forma razonable, pero no de forma tal que sugiera que tiene el apoyo del licenciante o lo recibe por el uso que hace. 